\title{
Aerobic Exercise Affects Myostatin Expression in Aged Rat Skeletal Muscles: A Possibility of Antiaging Effects of Aerobic Exercise Related With Pelvic Floor Muscle and Urethral Rhabdosphincter
}

Il Gyu Ko ${ }^{1,2}$, Jin Woo Jeong ${ }^{3}$, Young Hoon Kim³ , Yong Seok Jee², Sung Eun Kim¹, Sang Hoon Kim¹ , Jun Jang Jin ${ }^{1}$, Chang Ju Kim $^{1}$, Kyung Jin Chung ${ }^{3}$

${ }^{1}$ Department of Physiology, Kyung Hee University School of Medicine, Seoul;

${ }^{2}$ Department of Exercise Physiology · Prescription, Graduate School of Health Promotion, Hanseo University, Seosan;

${ }^{3}$ Department of Urology, Gachon University Gil Medical Center, Gachon University School of Medicine, Incheon, Korea

\begin{abstract}
Purpose: Aging-induced loss of muscle mass and subsequent reduction of strength is a fundamental cause of frailty, functional decline, and disability. And this may lead to muscular dysfunction, voiding dysfunction, or urinary incontinence due to pelvic muscle weakness induced by aging. Physical exercise has been recommended for the prevention and the treatment of these agerelated frail states. We investigated the effects of treadmill exercise on muscle strength, myostatin mRNA and protein expression, and gastrocnemius myocytes proliferation in aged rats to investigate the possible antiaging effects of aerobic exercise on skeletal muscles such as pelvic floor muscles and urethral rhabdosphincter muscle.

Methods: In this study, 5-month-old male Sprague-Dawley rats were used as the young-age group $(\mathrm{n}=20)$ and 24-month-old rats were used as the old-age group $(n=20)$. Each group was randomly divided into two groups ( $\mathrm{n}=10$ in each group): the sedentary and the treadmill exercise group. The rats in the exercise groups were forced to run on a motorized treadmill for 30 minutes, once a day, for 6 weeks. For this study, a weight load test, hematoxylin and eosin staining, real-time and reverse transcription polymerase chain reaction for myostatin mRNA, myostatin western blot, and 5-bromo-2'-deoxyuridine immunohistochemistry were performed in the gastrocnemius muscle.

Results: The age-induced reduction of muscle mass and strength was associated with a decrease in myocyte proliferation and an increase in myostatin mRNA and protein expression in the gastrocnemius. However, treadmill exercise improved muscle mass and strength through suppression of myostatin mRNA and protein expression, and myocyte proliferation increase in the gastrocnemius against the aging process.

Conclusions: Aerobic exercise is a useful strategy for enhancing muscle function against aging-induced loss of skeletal muscle mass and functions.
\end{abstract}

Keywords: Aging; Exercise; Myostatin; Skeletal muscle; Muscle cell

\section{INTRODUCTION}

Aging is associated with a progressive decline of muscle mass, strength, and quality, a condition described as sarcopenia. Weakness in mobility resulting from muscle loss predates ma- jor physical disability and mortality, and is associated with poor quality of life and needs for health care [1]. Moreover, sarcopenia has become a major public health concern for the current aging society. In the urologic field, reduction of muscle mass might be one cause of functional deterioration such as voiding
Corresponding author: Kyung Jin Chung

Department of Urology, Gachon University Gil Medical Center, Gachon University School of Medicine, 21 Namdong-daero 774beon-gil, Namdong-gu, Incheon 405-760, Korea

Tel: +82-32-460-3336 / Fax: +82-32-460-3009 / E-mail: kjchung@gilhospital com.

Submitted: April 24, 2014 / Accepted after revision: May 30, 2014
This is an Open Access article distributed under the terms of the Creative Commons Attribution Non-Commercial License (http://creativecommons.org/licenses/by-nc/3.0/) which permits unrestricted non-commercial use, distribution, and reproduction in any medium, provided the original work is properly cited. 
dysfunction, including urinary incontinence. This muscle mass reduction is caused by multiple mechanisms, including preferential type II myofiber atrophy as a result of motor neuron death [2], physical inactivity [3,4], altered hormonal status, decreased caloric and protein intake, inflammatory mediators, stress, and alteration of the synthesis of various proteins [3].

Myostatin (growth differentiation factor-8), a member of the transforming growth factor- $\beta$ superfamily, acts as a negative regulator of myogenesis. It suppresses myoblast proliferation and myogenic differentiation [5]. Myostatin null animals display a significantly greater muscle mass, resulting from muscle fiber hyperplasia and hypertrophy [6]. Myostatin inhibits satellite cell activation in mice, and this has significant consequences in the context of aging-related muscle wasting and regeneration [7-9]. Therefore, considerable attention has been focused on whether therapeutic interventions can suppress myostatin signaling for the purpose of ameliorating or attenuating the effects of advancing age on skeletal muscle mass and function [10]. It has also been suggested that myostatin inhibits human urethral rhabdosphincter satellite cell proliferation; therefore, inhibition of myostatin function might be a useful strategy for the treatment of stress urinary incontinence [11].

Physical exercise has been recommended for the prevention and treatment of many chronic diseases associated with aging. Several studies showed that exercise training improved muscle age-related functional decline [12,13]. Moreover, physical exercise enhanced muscle metabolism, protein synthesis, and mitochondrial biogenesis in the elderly [14]. Pelvic floor muscle activation and strength components were also found to influence female urinary incontinence. Thus, pelvic muscle training is recommended as a first-line therapy for stress urinary incontinence [15]. Although resistance training such as a weight lifting was reported to increase muscle mass and strength even in the frail elderly [16], it may also have side effects such as hypertension and skeletal muscle injury. Therefore, it is not easy for the sedentary elderly to perform resistance exercise. There is a possibility that aerobic exercise may also reduce, prevent, and treat sarcopenia. Moreover, aerobic exercise is more appealing to many sedentary elders.

Stress urinary incontinence (SUI) is a representative agingrelated disease, which is observed in $64.9 \%$ of postmenopausal women [17]. Although SUI has various causes and the exact mechanisms are poorly understood, anatomical changes and dysfunction of the intrinsic urethral sphincter is considered as one of the major causes of SUI [18]. Moreover, it was recently reported that inhibition of myostatin function can stimulate urethra rhabdosphincter cell regeneration to treat SUI [11]. This anatomical change in urethral support and dysfunction of the intrinsic urethral sphincter partly contribute to involuntary urine loss during activities that cause abdominal straining. Thus, pelvic muscle exercise has been known to increase muscle mass and strength, and to reduce incontinence [19]. Additionally, we also reported that swimming alleviated SUI [20]. However, the exact mechanism remains unknown.

In the present study, we investigated the effects of treadmill exercise on muscle strength, myostatin expression, and myocytes proliferation in the rat gastrocnemius muscle to investigate the possible antiaging effect of aerobic exercise on skeletal muscle. This study might shed new light on the mechanism involved in exercise-induced improvement of aging-related functional decline of muscles.

\section{MATERIALS AND METHODS}

\section{Experimental Animals and Treatment}

Five-month-old male Sprague-Dawley rats $(\mathrm{n}=20,310 \pm 10 \mathrm{~g})$ and 24-month-old rats $(n=20,410 \pm 20 \mathrm{~g})$ were used in this study. The experimental procedures were performed in accordance with the animal care guidelines of the National Institutes of Health and the Korean Academy of Medical Sciences. The rats were housed under controlled temperature $\left(23^{\circ} \mathrm{C} \pm 2^{\circ} \mathrm{C}\right)$ and 12-hour light/12-hour dark cycles with food and water available ad libitum. Each group of rats was randomly divided into 2 groups ( $\mathrm{n}=10$ in each group) according to exercise: the young-age sedentary group, the young-age treadmill exercise group, the old-age sedentary group, and the old-age treadmill exercise group. All rats received $50 \mathrm{mg} / \mathrm{kg}$ 5-bromo-2'-deoxyuridine (BrdU; Sigma Chemical Co., St. Louis, MO, USA) intraperitoneally once a day 30 minutes before the beginning of the treadmill exercise for 6 weeks.

\section{Treadmill Exercise Protocol}

The rats in the exercise groups were forced to run on a motorized treadmill for 30 minutes, once a day, for 6 weeks. The exercise load consisted of running at a speed of $2 \mathrm{~m} / \mathrm{min}$ for the first 5 minutes, $5 \mathrm{~m} / \mathrm{min}$ for the next 5 minutes, and then $8 \mathrm{~m} / \mathrm{min}$ for the last 20 minutes, at a $0^{\circ}$ inclination. The animals in the nonexercise groups were left on the treadmill, without running, for the same period as the exercise group. 


\section{Weight Load Test}

To evaluate walking tension, a weight load test was performed 40 days after the beginning of the experiment. The weight load test measured the weight placed on each limb during voluntary walking. This apparatus is composed of a starting box (translucent), a path, and an arrival box (dark). When the starting box was illuminated with a bright light, rats in the starting box moved voluntarily toward the arrival box without stopping or turning around. The path of the apparatus was constructed to monitor weight load of a rat leg at a maximum of 4 different spots along the path. The floor of the path consisted of eight acrylic plates $(5 \mathrm{~cm} \times 10 \mathrm{~cm})$ attached to a load cell (working range $0-1,000$ g, DACELL Ltd., Cheongwon, Korea). These plates were lined up in two rows of four. The output of each load cell was fed to a digital amplifier (Cyber Amp 380, Axon Instruments Inc., Union City, CA, USA) for appropriate amplification and filtering. The processed signal was sent to a personal computer via analog-digital converter (1401 Plus, Cambridge Electronic Design, Cambridge, UK) and plotted as a time-weight load curve using a software program (Spike, Cambridge Electronic Design). The weight load value measured at a given time was expressed in percent of body weight.

\section{Tissue Preparation}

The rats were euthanized immediately after the second weight load test (after 42 days of daily treadmill exercises). The animals were anesthetized using Zoletil $50(10 \mathrm{mg} / \mathrm{kg}$, intraperitoneally; Vibac Laboratories, Carros, France) and the gastrocnemius muscle was removed. The muscle tissues were fixed in $4 \%$ paraformaldehyde, dehydrated in graded ethanol, treated in xylene, and infiltrated and embedded in paraffin. Coronal sections (5 $\mu \mathrm{m}$ in thickness) were cut by using a paraffin microtome (Thermo Co., Cheshire, UK) and mounted on coated slides, and then dried at $37^{\circ} \mathrm{C}$ overnight on a hot plate. On average, six sections were collected for each muscle.

\section{RNA Extraction and Reverse Transcription-Polymerase Chain Reaction}

Total RNA was extracted from muscle tissue using TRIzol reagent (Invitrogen, Carlsbad, CA, USA) according to the manufacturer's protocol. An aliquot of total RNA was reverse transcribed and amplified using MMLV reverse transcriptase (RT) and Taq DNA polymerase (Promega, Madison, WI, USA) respectively. One microgram of total RNA was added to $0.5 \mu \mathrm{g}$ oligo (dT) in Diethylpyrocrbonate-treated water and incubated at $70^{\circ} \mathrm{C}$ for 5 minutes and $4^{\circ} \mathrm{C}$ for 5 minutes. A total of $1 \mathrm{mM}$ of all four deoxyribonucleotides (dNTPs), $5 \mu \mathrm{L}$ of $5 \mu$ RT buffer, and 200 units of superscript II RT were added. The samples were incubated at $42^{\circ} \mathrm{C}$ for 1 hour followed by 10 minutes at $75^{\circ} \mathrm{C}$ and stored at $4^{\circ} \mathrm{C}$. Polymerase chain reaction (PCR) amplification was performed using a PTC-0150 MiniCycler (BioRad, Hercules, CA, USA) in a reaction volume of $40 \mu \mathrm{L}$ containing $1 \mu \mathrm{L}$ of the appropriate $\mathrm{CDNA}, 0.5 \mu \mathrm{L}$ of each primer set at a concentration of $10 \mathrm{pM}, 4 \mu \mathrm{L}$ of $10 \mu \mathrm{RT}$ buffer, $1 \mu \mathrm{L}$ of $2.5 \mathrm{mM}$ dNTP, and $0.2 \mu \mathrm{L}$ of Taq DNA polymerase (Takara, Shiga, Japan). Following primers used are given with sequences: GAPDH forward, 5'-AAC TTT GGC ATT GTG GAA GG-3' (20 mer) and reverse, 5' -ACA CAT TGG GGG TAG GAA CA-3' (20 mer); Myostatin forward, $5^{\prime}$-CTA CCA CGG AAA CAA TCA TTA-3' (21 mer) and reverse, 5'-AGC AAC ATT TGG GCT TTC CAT-3' (21 mer).

\section{Real-Time PCR}

For the LightCycler reaction, a mastermix of the following reaction components was prepared: $2.2 \mu \mathrm{L}$ water, $0.4 \mu \mathrm{L}$ forward primer, $0.4 \mu \mathrm{L}$ reverse primer and $5 \mu \mathrm{L}$ SYBR premix EX taq (RR041A, Takara, Shiga, Japan). LightCycler mastermix (8 $\mu \mathrm{L})$ was filled in the LightCycler glass capillaries and $1 \mu \mathrm{L}$ cDNA was added as the PCR template. Capillaries were closed, centrifuged and placed into the LightCycler rotor. The following LightCycler experimental protocol was used: denaturation program $\left(95^{\circ} \mathrm{C}\right.$ for 3 minutes), amplification program repeated 50 times $\left(95^{\circ} \mathrm{C}\right.$ for 5 seconds, $60^{\circ} \mathrm{C}$ for 10 seconds, $72^{\circ} \mathrm{C}$ for 20 seconds), melting curve program $\left(60^{\circ} \mathrm{C}-95^{\circ} \mathrm{C}\right.$ with a heating rate of $0.1^{\circ} \mathrm{C}$ per second and a continuous fluorescence measurement), and finally a cooling step to $40^{\circ} \mathrm{C}$ for 30 seconds. For the mathematical model, it is necessary to determine the crossing point (CP) for each transcript. $\mathrm{CP}$ is defined as the point at which the fluorescence rises appreciably above the background fluorescence. "Fit Point Method' was performed in the LightCycler software 3.3 (Roche Diagnostics, Basel, Switzerland), CP was measured at a constant level of fluorescence. Following primers used are given with sequences: GAPDH forward, 5'-AAC TTT GGC ATT GTG GAA GG-3' (20 mer) and reverse, 5'-ACA CAT TGG GGG TAG GAA CA-3' (20 mer); Myostatin forward, 5'-CTA CCA CGG AAA CAA TCA TTA-3' (21 mer) and reverse, 5' AGC AAC ATT TGG GCT TTC CAT-3' (21 mer).

\section{Western Blot}

The muscle tissues were collected, and immediately frozen at 
$-70^{\circ} \mathrm{C}$. The tissues were homogenized with lysis buffer containing $50 \mathrm{mM}$ Tris- $\mathrm{HCl}$ (pH 8.0), $150 \mathrm{mM} \mathrm{NaCl}, 10 \%$ glycerol, $1 \%$ Triton X-100, $1.5 \mathrm{mM} \mathrm{MgCl} \cdot 6 \mathrm{H}_{2} \mathrm{O}, 1 \mathrm{mM}$ ethylene glycol tetraacetic acid, $1 \mathrm{mM}$ phenylmethylsulfonyl fluoride, $1 \mathrm{mM} \mathrm{Na} 2$ $\mathrm{VO}_{4}$, and $100 \mathrm{mM} \mathrm{NaF}$, and then centrifuged at 14,000 rpm for 30 minutes. The protein content was measured using a Bio-Rad colorimetric protein assay kit (Bio-Rad). Thirty micrograms of protein were separated on sodium dodecyl sulfate-polyacrylamide gels and transferred to a nitrocellulose membrane. Mouse GAPDH antibody (1:3,000 Cell Signaling Technology, Beverly, MA, USA), rabbit antimyostatin antibody (1:1,000; Millipore, Billerica, MA, USA) were used as primary antibodies. Horseradish peroxidase-conjugated antimouse antibody (1:2,000; Amersham Pharmacia Biotech GmbH, Freiburg, Germany), and horseradish peroxidase-conjugated antirabbit antibody (1:3,000; Vector Laboratories, Burlingame, CA, USA) were used as secondary antibodies. The experiment was performed in normal laboratory conditions and at room temperature except for the membrane transfer, which was performed at $4^{\circ} \mathrm{C}$ using a cold pack and prechilled buffer. Band detection was performed using the enhanced chemiluminescence detection kit (Santa Cruz Biotechnology, Dallas, CA, USA).

\section{Hematoxylin and Eosin Staining}

To detect histological changes in the muscles, hematoxylin and eosin (H\&E) staining was performed. The slides were dipped into Mayer's hematoxylin for 30 seconds, and then rinsed with tap water until clear, dipped in eosin 30 seconds, and rinsed again with water The slides were air-dried at room temperature and then dipped twice in 95\% ethanol, twice in 100\% ethanol, twice in a solution of $50 \%$ ethanol and 50\% xylene, and twice in $100 \%$ xylene. The coverslips were finally mounted using Permount (Fisher Scientific, Waltham, MA, USA).

\section{BrdU Immunohistochemistry}

To detect newly generated myocytes in the muscles, BrdU-specific immunohistochemistry was performed. Paraffin embedded muscle section slides were deparaffinized in xylene and rehydrated in graded alcohols, followed by a 5-minute wash in running water. Tissues were denatured for 10 minutes in boiling $10 \mathrm{mM}$ citric acid (pH 6.0) and allowed to return to room temperature for 10 minutes. The sections were first permeabilized by incubation in $0.5 \%$ Triton X-100 in phosphate buffered saline (PBS) for 20 minutes, then pretreated in 50\% formamide- $2 \times$ st andard saline citrate at $65^{\circ} \mathrm{C}$ for 2 hours, denatured in $2 \mathrm{~N} \mathrm{HCl}$ at $37^{\circ} \mathrm{C}$ for 30 minutes, and rinsed twice in $100 \mathrm{mM}$ sodium borate $\left(\mathrm{pH}\right.$ 8.5). The sections were then incubated overnight at $4^{\circ} \mathrm{C}$ with a BrdU-specific mouse monoclonal antibody (1:600; Roche, Mannheim, Germany). The sections were then washed three times with PBS and incubated with biotinylated mouse secondary antibody (1:200; Vector Laboratories) for 1 hour. The sections were then incubated for another 1 hour with an avidinperoxidase complex (1:100; Vector Laboratories). For visualization, sections were incubated in $50 \mathrm{mM}$ Tris- $\mathrm{HCl}$ (pH 7.6) containing $0.03 \%$ diaminobenzidine, and $0.03 \%$ hydrogen peroxide for 5 minutes. The slides were air-dried overnight at room temperature and coverslips were mounted using Permount (Fisher Scientific).

\section{Data Analysis}

To compare myostatin relative expression, densitometric analysis of the detected bands was performed using the Molecular Analyst ver. 1.4.1 (Bio-Rad). The cross-section areas of muscle tissue from each slice was measured using Image-Pro Plus computer-assisted image analysis system (Media Cyberbetics Inc., Silver Spring, MD, USA) attached to a light microscope (Olympus Co., Tokyo, Japan). The BrdU-positive myocytes in the muscle tissue were counted. The number of BrdU-positive myocytes was expressed as the number of myocytes per square millimeter of all area in the muscle tissues.

Statistical analysis was performed using one-way analysis of varivance followed by Duncan's post hoc test, and the results are expressed as the mean \pm standard error of the mean. Significance was set as $\mathrm{P}<0.05$.

\section{RESULTS}

\section{Effects of Treadmill Exercise on Walking Strength in the Weight Load Test}

The walking strength results obtained from the weight load test are presented in Fig. 1. When the weight load in the young-age sedentary group was set as $100 \%$, the level of weight load was $110.18 \% \pm 3.61 \%$ in the young-age treadmill exercise group, $81.94 \% \pm 2.01 \%$ in the old-age sedentary group, and $91.89 \% \pm$ $2.07 \%$ in the old-age treadmill exercise group.

These results showed that walking strength in the weight load test was significantly decreased in the old-age rats $(\mathrm{P}<0.05)$ and treadmill exercise alleviated aging-induced decrease of walking strength $(\mathrm{P}<0.05)($ Fig. 1). 


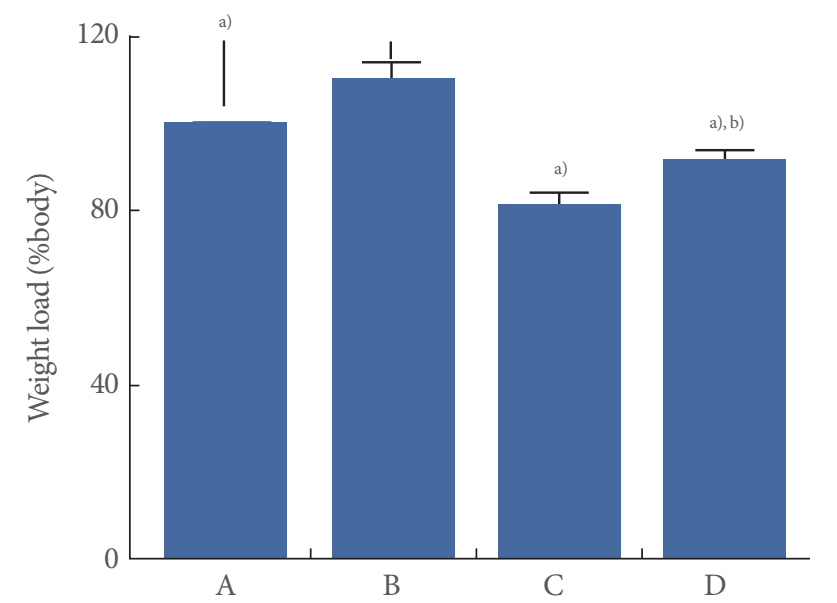

Fig. 1. Effect of treadmill exercise on walking strength in weight load test. (A) Young-aged sedentary group, (B) young-aged treadmill exercise, (C) old-aged sedentary group, and (D) oldaged treadmill exercise group. ${ }^{\text {a) }} \mathrm{P}<0.05$ compared to the youngaged sedentary group. ${ }^{\text {b) }} \mathrm{P}<0.05$ compared to the old-aged sedentary group.

\section{Effect of Treadmill Exercise on the Gastrocnemius Histological Alteration}

The gastrocnemius histological alterations are presented in Fig. 2. After H\&E staining, the gastrocnemius tissue in old-age rats displayed subjectively greater numbers of hypertrophy in muscle fibers and a substantial amount of connective tissue within the perimysium compared to the young-age rat muscle. However, compared to old-age sedentary rats, treadmill exercise during 6 weeks reduced atrophic muscle fiber and connective tissue within the perimysium in the gastrocnemius of old-age treadmill exercised rats (Fig. 2).

\section{Effect of Treadmill Exercise on Myostatin mRNA Level in the Muscle}

Myostatin mRNA levels are presented in Fig. 3. When myostatin mRNA level in the young-age sedentary group was set as 100.00 , myostatin mRNA level was $72.59 \pm 16.06$ in the youngage treadmill exercise group, 537.36 \pm 63.07 in the old-age sedentary group, and $222.89 \pm 19.08$ in the old-age treadmill exercise group.

These results showed that myostatin mRNA expression in the muscle was significantly increased in the old-age rats $(\mathrm{P}<0.05)$ and treadmill exercise suppressed aging-induced myostatin mRNA expression $(\mathrm{P}<0.05)$ (Fig. 3).
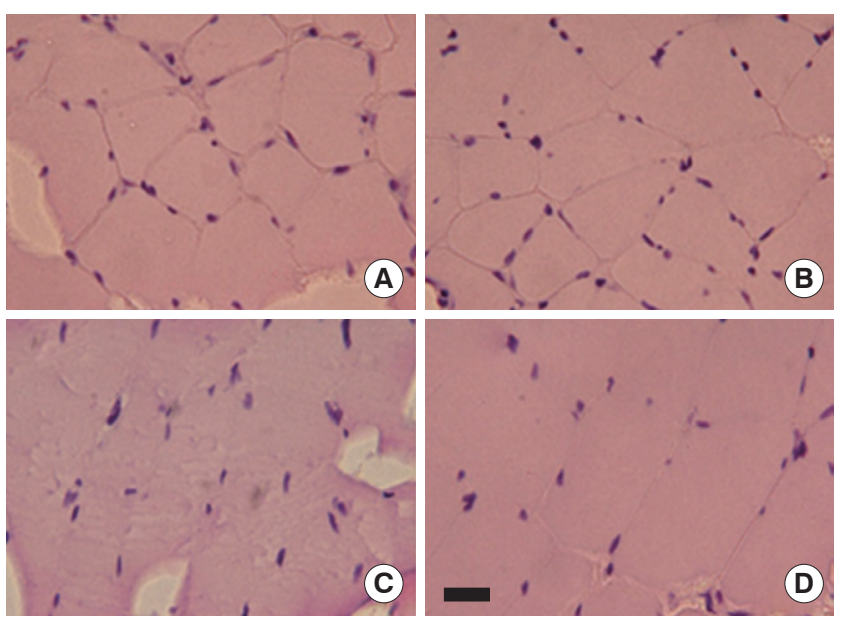

Fig. 2. Effect of treadmill exercise on histological alteration in the muscle. Photomicrographs of cross-section area in the gastrocnemius. Section were stained for hematoxylin and eosin. Scale bar $250 \mu \mathrm{m}$. (A) Young-aged sedentary group, (B) youngaged treadmill exercise, (C) old-aged sedentary group, and (D) old-aged treadmill exercise group.

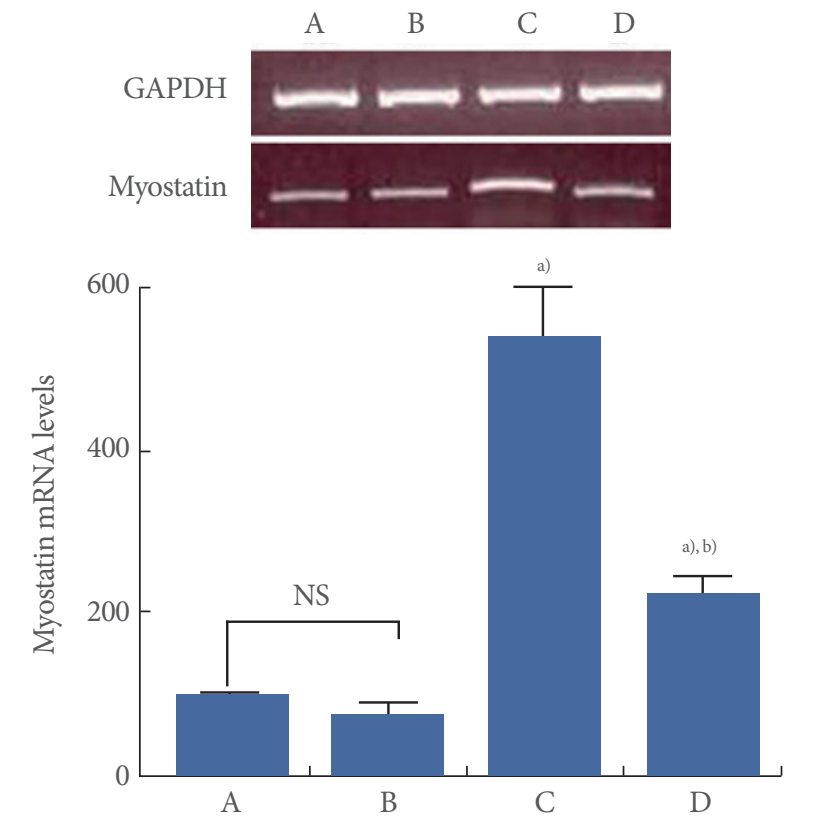

Fig. 3. Effect of treadmill exercise on myostatin mRNA expression in the muscle. GAPDH was used as an internal control. Upper: The results of band detection using reverse transcription polymerase chain reaction (PCR) method. Lower: The levels of myostatin mRNA following real-time PCR. (A) Young-aged sedentary group, (B) young-aged treadmill exercise, (C) oldaged sedentary group, and (D) old-aged treadmill exercise group. ${ }^{\text {a) }} \mathrm{P}<0.05$ compared to the young-aged sedentary group. b) $\mathrm{P}<0.05$ compared to the old-aged sedentary group. NS, nonsignificant. 


\section{Effect of Treadmill Exercise on Myostatin Protein Level in the Muscle}

Myostatin protein levels are presented in Fig. 4. When myostatin protein level in the young-age sedentary group was set as 1.00 , myostatin protein level was $1.02 \pm 0.06$ in the young-age treadmill exercise group, $1.74 \pm 0.08$ in the old-age sedentary group, and $1.35 \pm 0.07$ in the old-age treadmill exercise group.

These results showed that myostatin protein expression in the muscle was significantly increased in the old-age rats $(\mathrm{P}<0.05)$ and treadmill exercise suppressed aging-induced myostatin protein expression $(\mathrm{P}<0.05)($ Fig. 4).

\section{Effect of Treadmill Exercise on Myocyte Proliferation in the Muscle}

Micrographs of BrdU-positive cells in the muscle are presented in Fig. 5. The number of BrdU-positive cell was 74.69 \pm 7.16 / $\mathrm{mm}^{2}$ in the young-age sedentary group, $131.13 \pm 12.73 / \mathrm{mm}^{2}$ in the young-age treadmill exercise group, $28.24 \pm 5.08 / \mathrm{mm}^{2}$ in the old-age sedentary group, and $50.70 \pm 5.89 / \mathrm{mm}^{2}$ in the old-

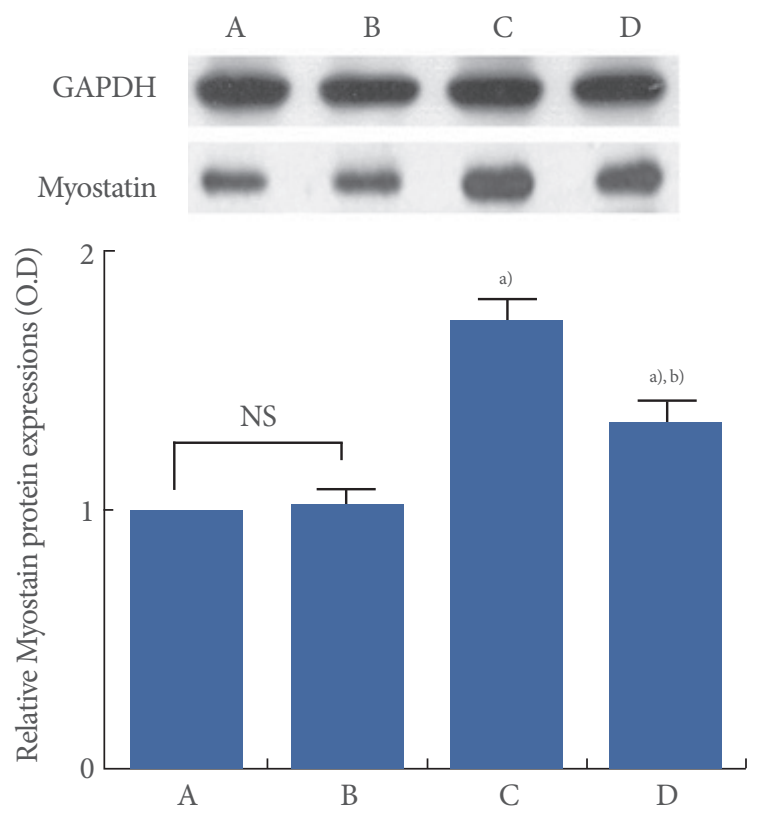

Fig. 4. Effect of treadmill exercise on the expression of myostatin protein. GAPDH was used as an internal control. Upper: The results of band detection using the enhanced chemiluminescence. Lower: The relative expression of myostatin protein. (A) Young-aged sedentary group, (B) young-aged treadmill exercise, (C) old-aged sedentary group, and (D) old-aged treadmill exercise group. ${ }^{\text {a }} \mathrm{P}<0.05$ compared to the young-aged sedentary group. ${ }^{\text {b) }} \mathrm{P}<0.05$ compared to the old-aged sedentary group. NS, nonsignificant. age treadmill exercise group.

These results showed that myocytes proliferation in the muscle was significantly decreased in the old-age rats $(\mathrm{P}<0.05)$, whereas, treadmill exercise enhanced aging-induced decrease of myocyte proliferation $(\mathrm{P}<0.05)($ Fig. 5).

\section{DISCUSSION}

Aging-related muscle reduction is a direct cause of several agerelated muscle diseases. Low physical activity levels were observed in elderly people, and muscle strength is a critical component of walking ability. This decline in muscle strength is directly correlated with loss of skeletal muscle fibers and increased muscle fiber atrophy.

Several studies in the urologic field showed that exercise
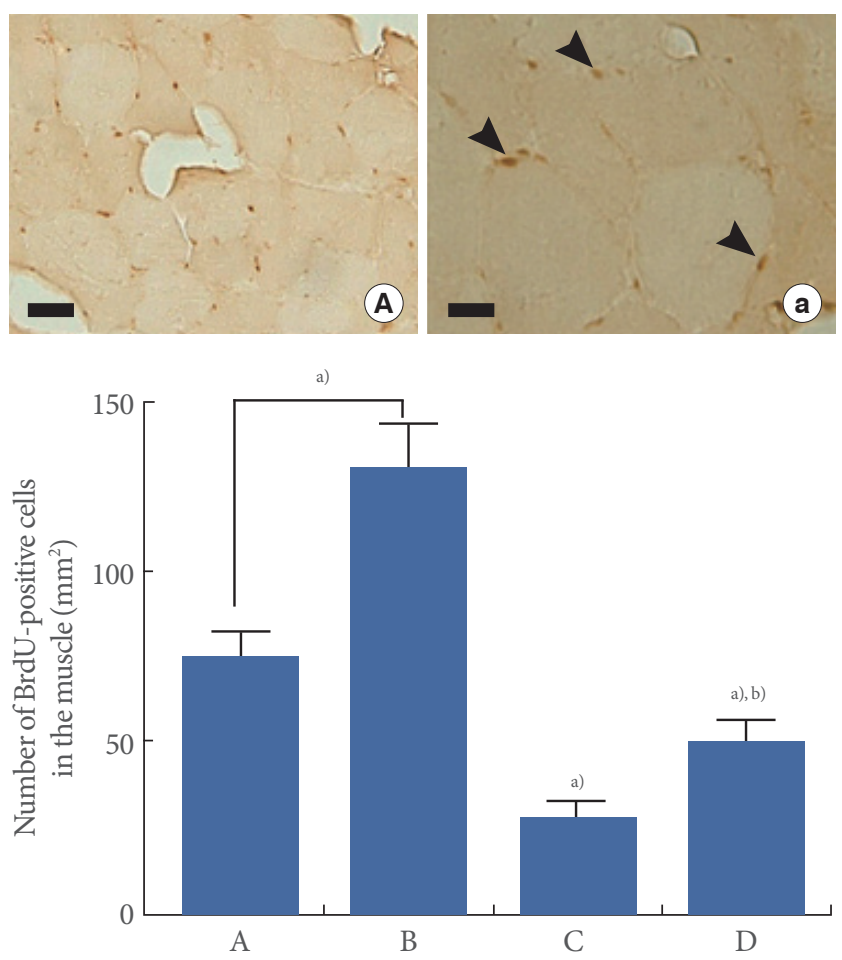

Fig. 5. Effect of treadmill exercise on myocyte proliferation in the muscle. Upper: Photomicrographs of 5-bromo-2'-deoxyuridine (BrdU) positive myocytes in the muscle. Sections were stained for BrdU (black arrowheads). Scale bar $150 \mu \mathrm{m}$ (A) and $400 \mu \mathrm{m}$ (a). Lower: Number of BrdU-positive cells in each group. (A) Young-aged sedentary group, (B) young-aged treadmill exercise, (C) old-aged sedentary group, and (D) old-aged treadmill exercise group. ${ }^{\text {a }} \mathrm{P}<0.05$ compared to the young-aged sedentary group. ${ }^{\text {b) }} \mathrm{P}<0.05$ compared to the old-aged sedentary group. 
training improved muscle age-related functional decline. Women with pelvic organ prolapse have reduced pelvic floor muscle strength and reduced pelvic floor muscle thickness, and there is an association between pelvic muscle thickness and pelvic floor muscle strength in human [21]. In one study, women in the urinary incontinence group (mixed, urge, and stress) showed a successive decrease of electromyography activity with increasing age [22]. Furthermore, magnetic resonance imaging studies showed that the forward displacement and compression produced by the levator ani muscle is smaller in older than in younger women [23]. Thus, pelvic floor muscle training is one possible exercise therapy to reduce functional disorders like stress urinary incontinence and pelvic organ prolapse, which are probably of muscular origin [19]. The urethral sphincter muscle, which is the major muscle responsible for the urinary continent system, is composed of a thin inner layer of smooth muscle and a thick outer layer of striated muscle [24]. Apoptosis of the external rhabdosphincter cells is suggested as one of the major underlying causes of stress urinary incontinence [25]. Thus, although a large part of the low urinary tract symptoms, which are reduction in bladder capacity, uninhibited contractions, and diminished urethral pressure, are related to the aging-bladder itself [26], aging-related reduction of muscle changes can also affect the low urinary tract symptoms [24,25]. Because proving the effect of exercise on the pelvic floor muscles or urethral rhabdosphincter muscle in animal models remains difficult, we analyzed the effect of an exercise regimen such as treadmill exercise on the gastrocnemius muscle which is most representative muscle in exercise related research in an old-age rat model to determine the effect of exercise on sarcopenia and the antiaging effect of pelvic floor muscle training. We evaluated the aging-induced alteration of walking ability, such as speed and ground tension (walking strength) using a weight load test. In addition, histological alteration of cross sectional area in the muscle was measured using H\&E staining. Cross sectional areas of the gastrocnemius in old-age rats showed muscle fiber hypertrophy and a substantial amount of connective tissue within the perimysium compared to the young-age rat muscle. Walking strength in the weight load test was decreased in the old-age rats compared to the young-age rats. Such changes in muscle histological alteration and walking strength indicate that aging induced a decrease in muscle function. Our findings support previous reports indicating that aging decreased muscle strength through increased muscle fiber hypertrophy in human and animals $[27,28]$.
Various proteins are implicated in the reduction of muscle mass and hypertrophy in muscle fiber according to the normal aging process. Among them, myostatin is a regulator of skeletal muscles, and it plays a key role in the development and the maintenance of muscles. Myostatin levels increase with muscle atrophy due to neuromuscular inactivity, and with severe muscle wasting in elderly and myoatrophy patients [29]. Therefore, increased myostatin level in human muscles potentially explains the underlying mechanism of decrease muscle mass in sarcopenia. Additionally, myostatin is known to affect myocytes proliferation [6]. It was reported that the beneficial effect of myostatin deficiency is greater in elderly mice [29].

In this study, the expression of myostatin mRNA in the gastrocnemius was significantly increased in the old-age rats compared to young-age rats. Moreover, myostatin protein expression was enhanced in the old-age rats, indicating that aging induced myostatin expression. In addition, these alterations led to the suppression of myocyte proliferation in the muscle. The present results showed that myocyte proliferation in the gastrocnemius was reduced in the old-age rats compared to youngage rat. The current data demonstrated that myocyte proliferation was decreased with increasing expression of myostatin by aging. Our findings support previous reports indicating that aging-induced increase in myostatin expression caused the suppression of myocyte proliferation [30].

Treatments of aging related muscular weakness focus on the increment of muscle mass and strength, improvement of functional performance, and reduction of disability. Aerobic exercise can acutely increase muscle protein synthesis in healthy, independent older people [31]. A previous study reported that long-term aerobic exercise reduced myostatin mRNA levels in rat muscles [32].

In the present study, treadmill exercise decreased myostatin mRNA and protein expression in the gastrocnemius of old-age rats, showing that treadmill exercise ameliorated aging-induced myostatin expression in old-age rats. Furthermore, treadmill exercise induced an increase in myocyte proliferation in oldage rats by suppressing myostatin expression. Treadmill exercise induced alterations that led to a change in muscle fiber and strength levels. Progressive endurance exercise has also been shown to increase muscle mass, strength, and function in elderly people [33]. Moreover, several studies reported that longterm aerobic exercise such as treadmill running and bicycle increased the synthesis of myofibrillar muscle protein both in young and old adults [34,35]. 
Here, we showed that aerobic exercise could help overcome aging-induced decreasing of myocyte proliferation and downregulation of myostatin expression, thus facilitating sarcopenia recovery following aging. These effects might re-enforce pelvic floor and urethral sphincter muscles and support the recovery from functional deteriorations like stress urinary incontinence and pelvic organ prolapse, which are partially of muscular origin.

\section{CONFLICT OF INTEREST}

No potential conflict of interest relevant to this article was reported.

\section{ACKNOWLEDGEMENTS}

This study was supported by the National Research Foundation of Korea Grant funded by the Korean Government (NRF2011-35C-G00230).

\section{REFERENCES}

1. Ferrucci L, Guralnik JM, Buchner D, Kasper J, Lamb SE, Simonsick EM, et al. Departures from linearity in the relationship between measures of muscular strength and physical performance of the lower extremities: the Women's Health and Aging Study. J Gerontol A Biol Sci Med Sci 1997;52:M275-85.

2. Hunter GR, McCarthy JP, Bamman MM. Effects of resistance training on older adults. Sports Med 2004;34:329-48.

3. Doherty TJ. Invited review: aging and sarcopenia. J Appl Physiol (1985) 2003;95:1717-27.

4. Macaluso A, De Vito G. Muscle strength, power and adaptations to resistance training in older people. Eur J Appl Physiol 2004;91:45072.

5. McPherron AC, Lawler AM, Lee SJ. Regulation of skeletal muscle mass in mice by a new TGF-beta superfamily member. Nature 1997;387:83-90.

6. Siriett V, Salerno MS, Berry C, Nicholas G, Bower R, Kambadur R, et al. Antagonism of myostatin enhances muscle regeneration during sarcopenia. Mol Ther 2007;15:1463-70.

7. Langley B, Thomas M, Bishop A, Sharma M, Gilmour S, Kambadur R. Myostatin inhibits myoblast differentiation by down-regulating MyoD expression. J Biol Chem 2002;277:49831-40.

8. Thomas M, Langley B, Berry C, Sharma M, Kirk S, Bass J, et al. Myostatin, a negative regulator of muscle growth, functions by in- hibiting myoblast proliferation. J Biol Chem 2000;275:40235-43.

9. McCroskery S, Thomas M, Maxwell L, Sharma M, Kambadur R. Myostatin negatively regulates satellite cell activation and self-renewal. J Cell Biol 2003;162:1135-47.

10. Lynch GS. Emerging drugs for sarcopenia: age-related muscle wasting. Expert Opin Emerg Drugs 2004;9:345-61.

11. Akita Y, Sumino Y, Mori K, Nomura T, Sato F, Mimata H. Myosta tin inhibits proliferation of human urethral rhabdosphincter satellite cells. Int J Urol 2013;20:522-9.

12. Koh TJ, Brooks SV. Lengthening contractions are not required to induce protection from contraction-induced muscle injury. Am J Physiol Regul Integr Comp Physiol 2001;281:R155-61.

13. Waters DL, Brooks WM, Qualls CR, Baumgartner RN. Skeletal muscle mitochondrial function and lean body mass in healthy exercising elderly. Mech Ageing Dev 2003;124:301-9.

14. Menshikova EV, Ritov VB, Fairfull L, Ferrell RE, Kelley DE, Goodpaster BH. Effects of exercise on mitochondrial content and function in aging human skeletal muscle. J Gerontol A Biol Sci Med Sci 2006;61:534-40.

15. Luginbuehl H, Baeyens JP, Taeymans J, Maeder IM, Kuhn A, Radlinger L. Pelvic floor muscle activation and strength components influencing female urinary continence and stress incontinence: a systematic review. Neurourol Urodyn 2014 Apr 9 [Epub]. http:// dx.doi.org/10.1002/nau.22612.

16. Hikida RS, Staron RS, Hagerman FC, Walsh S, Kaiser E, Shell S, et al. Effects of high-intensity resistance training on untrained older men. II. Muscle fiber characteristics and nucleo-cytoplasmic relationships. J Gerontol A Biol Sci Med Sci 2000;55:B347-54.

17. Ushiroyama T, Ikeda A, Ueki M. Prevalence, incidence, and awareness in the treatment of menopausal urinary incontinence. Maturitas 1999;33:127-32.

18. Rodriguez LV, Chen S, Jack GS, de Almeida F, Lee KW, Zhang R. New objective measures to quantify stress urinary incontinence in a novel durable animal model of intrinsic sphincter deficiency. Am J Physiol Regul Integr Comp Physiol 2005;288:R1332-8.

19. Bo K. Pelvic floor muscle training in treatment of female stress urinary incontinence, pelvic organ prolapse and sexual dysfunction. World J Urol 2012;30:437-43.

20. Ko IG, Kim SE, Kim BK, Shin MS, Kim CJ, Yim SJ, et al. Swimming: effects on stress urinary incontinence and the expression of nerve growth factor in rats following transabdominal urethrolysis. Int Neurourol J 2011;15:74-81.

21. Braekken IH, Majida M, Engh ME, Bo K. Are pelvic floor muscle thickness and size of levator hiatus associated with pelvic floor muscle strength, endurance and vaginal resting pressure in women 
with pelvic organ prolapse stages I-III? A cross sectional 3D ultrasound study. Neurourol Urodyn 2014;33:115-20.

22. Gunnarsson M, Mattiasson A. Female stress, urge, and mixed urinary incontinence are associated with a chronic and progressive pelvic floor/vaginal neuromuscular disorder: an investigation of 317 healthy and incontinent women using vaginal surface electromyography. Neurourol Urodyn 1999;18:613-21.

23. Constantinou CE, Hvistendahl G, Ryhammer A, Nagel LL, Djurh uus JC. Determining the displacement of the pelvic floor and pelvic organs during voluntary contractions using magnetic resonance imaging in younger and older women. BJU Int 2002;90:408-14.

24. Strasser H, Klima G, Poisel S, Horninger W, Bartsch G. Anatomy and innervation of the rhabdosphincter of the male urethra. Prostate 1996;28:24-31.

25. Strasser H, Tiefenthaler M, Steinlechner M, Eder I, Bartsch G, Konwalinka G. Age dependent apoptosis and loss of rhabdosphincter cells. J Urol 2000;164:1781-5.

26. Siroky MB. The aging bladder. Rev Urol 2004;6 Suppl 1:S3-7.

27. Nilwik R, Snijders T, Leenders M, Groen BB, van Kranenburg J, Verdijk LB, et al. The decline in skeletal muscle mass with aging is mainly attributed to a reduction in type II muscle fiber size. Exp Gerontol 2013;48:492-8.

28. Ryall JG, Schertzer JD, Lynch GS. Attenuation of age-related muscle wasting and weakness in rats after formoterol treatment: thera- peutic implications for sarcopenia. J Gerontol A Biol Sci Med Sci 2007;62:813-23.

29. Schirwis E, Agbulut O, Vadrot N, Mouisel E, Hourde C, Bonnieu A, et al. The beneficial effect of myostatin deficiency on maximal muscle force and power is attenuated with age. Exp Gerontol 2013; 48:183-90.

30. Deveaux V, Picard B, Bouley J, Cassar-Malek I. Location of myostatin expression during bovine myogenesis in vivo and in vitro. Reprod Nutr Dev 2003;43:527-42.

31. Sheffield-Moore M, Yeckel CW, Volpi E, Wolf SE, Morio B, Chinkes DL, et al. Postexercise protein metabolism in older and younger men following moderate-intensity aerobic exercise. Am J Physiol Endocrinol Metab 2004;287:E513-22.

32. Leiter JR, Peeler J, Anderson JE. Exercise-induced muscle growth is muscle-specific and age-dependent. Muscle Nerve 2011;43:828-38.

33. Cartee GD. Influence of age on skeletal muscle glucose transport and glycogen metabolism. Med Sci Sports Exerc 1994;26:577-85.

34. Ng YC, Nagarajan M, Jew KN, Mace LC, Moore RL. Exercise training differentially modifies age-associated alteration in expression of Na+-K+-ATPase subunit isoforms in rat skeletal muscles. Am J Physiol Regul Integr Comp Physiol 2003;285:R733-40.

35. Treat-Jacobson D, Bronas UG, Leon AS. Efficacy of arm-ergometry versus treadmill exercise training to improve walking distance in patients with claudication. Vasc Med 2009;14:203-13. 